\title{
Recollective experience in word and nonword recognition
}

\author{
JOHN M. GARDINER and ROSALIND I. JAVA \\ City University, London, England
}

\begin{abstract}
The functional relationship between memory and consciousness was investigated in two experiments in which subjects indicated when recognizing an item whether they could consciously recollect its prior occurrence in the study list or recognized it on some other basis, in the absence of conscious recollection. Low-frequency words, relative to high-frequency words, enhanced recognition accompanied by conscious recollection but did not influence recognition in the absence of conscious recollection. By contrast, nonwords compared with words enhanced recognition in the absence of conscious recollection and reduced recognition accompanied by conscious recollection. A third experiment showed that confidence judgments in recognizing nonword targets corresponded with recognition performance, not with recollective experience. These measures of conscious awareness therefore tap qualitatively different components of memory, not some unitary dimension such as "trace strength." The findings are interpreted as providing further support for the distinction between episodic memory and other memory systems, and also as providing more qualified support for theories that assume that recognition memory entails two components, one of which may also give rise to priming effects in implicit memory.
\end{abstract}

The nature of consciousness in relation to memory performance has once again become of central importance in memory research. This importance is reflected by the contemporary interest in studies of amnesia, a disorder in which the loss of recollective experience is the main presenting symptom (see Shimamura, 1986, for a review). It is also reflected by the many recent studies in which performance in explicit memory tests, defined as those in which the person is directed consciously to recollect prior events or experiences, has been compared with performance in implicit memory tests, defined as those in which the person is not so directed (see RichardsonKlavehn \& Bjork, 1988; Roediger, Weldon, \& Challis, 1989; Schacter, 1987, for reviews). These two sets of studies are linked by repetition, or direct priming, effects in implicit memory tests. In amnesic patients, such priming effects are typically found to be quite comparable with those found in memory-unimpaired adults. And, in memory-unimpaired adults, priming measures are typically uninfluenced, or influenced in different ways, by variables that influence performance in explicit memory tests. Furthermore, it has become increasingly clear from a number of other recent studies that memory in the absence of recollective experience influences the performance of memory-unimpaired adults in a wide variety of perceptual, judgmental, and estimation tasks (Jacoby, 1988; Jacoby, Kelley, \& Dywan, 1989).

\footnotetext{
We are grateful to Francesca Ahmed for collecting the data in Experiment 3. Requests for reprints should be addressed to John Gardiner, Memory \& Cognition Research Group, City University, Northampton Square, London ECIV OHB, England.
}

$$
\text { -Accepted by previous editor, Alice F. Healy }
$$

Despite this concern with the nature of consciousness in memory, there have been scarcely any attempts to directly measure conscious experience in relation to memory performance. Hitherto, the general strategy has been to manipulate consciousness, as in comparisons between implicit and explicit tests, to assess its influence indirectly, and to make various assumptions about the kinds of consciousness and the forms of memory involved. This situation may partly reflect what Tulving (1989) has called the doctrine of concordance of behavior, cognition, and experience. In general form, this doctrine holds that performance, knowledge, and experience are closely correlated. Acceptance of this doctrine implies that the relationship between memory performance and conscious experience is more a matter of rational analysis than empirical inquiry. The situation may also reflect what Watkins (in press) has called the doctrine of mediationism, that is, the prevailing theoretical emphasis on hypothetical mental constructs such as memory traces, mechanisms, processing modes, and the like. This emphasis on hypothetical mental entities leads all too readily to the exclusion of any concern with actual mental experience.

In this article, we describe two experiments in which the relationship between memory performance and conscious experience was measured empirically, adopting a procedure for doing this that was suggested by Tulving (1985b). In these experiments, subjects were required, when recognizing an item from a study list, to indicate whether they could consciously recollect its prior occurrence in the study list (in which case they responded ' $R$ '" for "remember") or recognized it on some other basis, in the absence of any recollective experience (in which case they responded " $K$ " for "know"). RichardsonKlavehn and Bjork (1988) prefer to reserve the terms ex- 
plicit and implicit memory for memory expressed with and without awareness of remembering, instead of using those terms to classify memory tests. According to their usage, therefore, these two measures correspond exactly with measures of explicit and implicit memory.

In a previous article in which these measures were used, it was found that they gave rise to dissociations between a person's conscious experience and his or her performance on recognition-memory tasks (Gardiner, 1988a). This research showed that levels of processing, generate versus read-study conditions, and retention interval-all variables whose influence on recognition-memory performance is well known-influenced only items whose recognition was accompanied by conscious recollection. Recognition performance in the absence of any recollective experience was quite uninfluenced by these variables.

These findings are important theoretically for Tulving's (1983, 1985a, 1985b) distinction between episodic memory and other memory systems. Because recollective experience (or "autonoetic consciousness") is a defining property of the episodic system, that distinction is materially strengthened by evidence that staple episodic memory phenomena such as levels-of-processing effects are indeed truly episodic as defined and measured by conscious awareness. The findings are also interesting because the form of dissociation observed resembles that which had been previously observed in comparisons of the effects of these independent variables on performance in explicit and implicit memory tests (e.g., Gardiner, 1988b; Jacoby \& Dallas, 1981; Tulving, Schacter, \& Stark, 1982). This parallel is consistent with theories that assume that recognition performance entails two different components, one of which may also give rise to priming effects in implicit tests. This second component has been thought of as increased familiarity (Mandler, 1980, 1988) or as relative perceptual fluency (Jacoby, 1988; Jacoby \& Dallas, 1981), and to reflect data-driven rather than conceptually driven processing (Jacoby, 1983; Roediger et al., 1989). Thus, as Gardiner (1988a) suggested, "remember" and "know" measures of conscious awareness may respectively correspond with conceptually driven and data-driven processes.

However, in the experiments described by Gardiner (1988a), recognition performance in the absence of conscious recollection was not only uninfluenced by the independent variables, it was also much lower than when recognition was accompanied by conscious recollection. This low level of performance makes it difficult to entirely discount the possibility that recognition in the absence of recollective experience might reflect only relatively weak "trace strength," rather than some qualitatively different component of memory-even though the form of dissociation obtained itself argues against this possibility, on the grounds that weak as well as strong memory traces should have been influenced by those variables, albeit to a lesser extent.

The main purpose of the present research was to provide further tests of the "dual-component hypothesis," that is, the hypothesis that these measures of conscious- ness reflect qualitatively distinct components of memory performance, rather than some unitary dimension such as trace strength. The dual-component hypothesis would prove hard to sustain if recognition in the absence of recollective experience is always found to be associated with low levels of performance, and is always found to be uninfluenced by independent variables. On the other hand, the hypothesis would be supported by evidence that recognition in the absence of recollective experience is sometimes associated with relatively high levels of performance and is systematically influenced by some independent variable.

\section{EXPERIMENT 1}

The purpose of Experiment 1 was to compare "remember" and "know" measures of conscious awareness in recognition memory for low-frequency and highfrequency words. The point of this comparison was to see whether recognition of the low-frequency words might be associated with an increase in the incidence of "know" responses. This possibility is suggested by the finding that low-frequency words, relative to high-frequency words, give rise to enhanced priming in perceptual identification (Jacoby \& Dallas, 1981), as well as enhanced performance in recognition memory (see Duchek \& Neely, 1989; Glanzer \& Adams, 1985; Gregg, 1976, for reviews), and by the view that both of these word-frequency effects are due to increased familiarity (Mandler, 1980) or perceptual fluency (Jacoby \& Dallas, 1981).

\section{Method}

Subjects. The subjects were 24 undergraduate students who were paid for their participation in the experiment and were tested individually.

Design and Materials. A set of 96 words, 48 low-frequency and 48 high-frequency, were selected from the Medical Research Council (MRC) psycholinguistic database described by Coltheart (1981). These low- and high-frequency words had mean frequency counts of 2 and 160, respectively, in Kučera and Francis's (1967) norms, and they each had the same mean imagery value of 609 , as calculated in the MRC database by merging three sets of norms to form a scale ranging from 100-700. There were equal numbers of one-, two-, and three-syllable words of each frequency. Examples of the low-frequency words are: KILT, BLOSSOM, TORNADO, ATHLETE, and HARP. Examples of the high-frequency words are: MONEY, RIVER, HOSPITAL, CAR, and PRESIDENT.

There were two alternate study lists, each consisting of 24 lowfrequency and 24 high-frequency words selected so that words of each syllabic length were assigned to each frequency level in each study list in equal proportions. Half of the subjects received one study list; half received the other study list. The recognition test consisted of all 96 words from the complete set; hence, target words for half the subjects were lure words for the other half. In this test, for each word the subjects recognized, they were asked to indicate whether they could or could not consciously recollect its prior occurrence in the study list.

Procedure. Study-list words were handprinted on a deck of cards and presented at the rate of $2 \mathrm{sec} /$ word in an order randomized separately for each subject. The subjects were told simply to memorize the words for a test to be given on the following day. The 24-h retention interval was intended to reduce the risk of ceiling effects in recognition performance. For the test, all 96 words in the com- 
plete set appeared, in a single constant order, typewritten in 4 columns of 24 words each. The subjects were given the following instructions to read:

In this test there are four columns of words; some of these words are from the cards you studied in the first part of the experiment, others are not.

Please work carefully down each column, indicating for each successive word whether you recognize it from the study cards or not. If you recognize a word, please encircle it.

Additionally, as you make your decision about recognizing a word, I would like you to bear in mind the following:

Often, when remembering a previous event or occurence, we consciously recollect and become aware of aspects of the previous experience. At other times, we simply know that something has occurred before, but without being able consciously to recollect anything about its occurrence or what we experienced at the time

Thus in addition to your indicating your recognition of a word from the original study set, I would like you to write either the letter ' $R$ ' after the encircled item, to show that you recollect the word consciously, or " $\mathrm{K}$ " if you feel you simply know that the word was in the previous study set.

So, for each word that you recognize, please write " $R$ " next to it if you recollect its occurtence, or " $\mathrm{K}$ " if you simply know that it was shown on the cards.

After the subjects had read these instructions, the experimenter gave further, oral instructions. Conscious recollection was described as the ability to become consciously aware again of some aspects of what happened and what was experienced at the time the word was presented-such as something to do with the physical appearance of the word, the way it was presented, something one was thinking of or did during the word's presentation, or something else one noticed in the laboratory at that time. Recognition on some other basis was described as recognizing that the word was from the study list but being unable consciously to recollect anything about the actual occurrence of the word, or what happened and was experienced at the time it was presented. This distinction between $R$ and $K$ judgments was further illustrated by more everyday examples. The subjects were told that their memory for the name of the last movie they watched would almost certainly be accompanied by conscious awareness of aspects of that particular event and experience, but that their memory for their own name would almost certainly not normally be accompanied by conscious awareness of any particular event or experience. This particular illustration was deliberately chosen to make it clear that the absence of recollective experience was not necessarily associated with poor memory. The subjects' understanding of these instructions was monitored and, after they had completed the test, the experimenter checked that the instructions had been followed properly.'

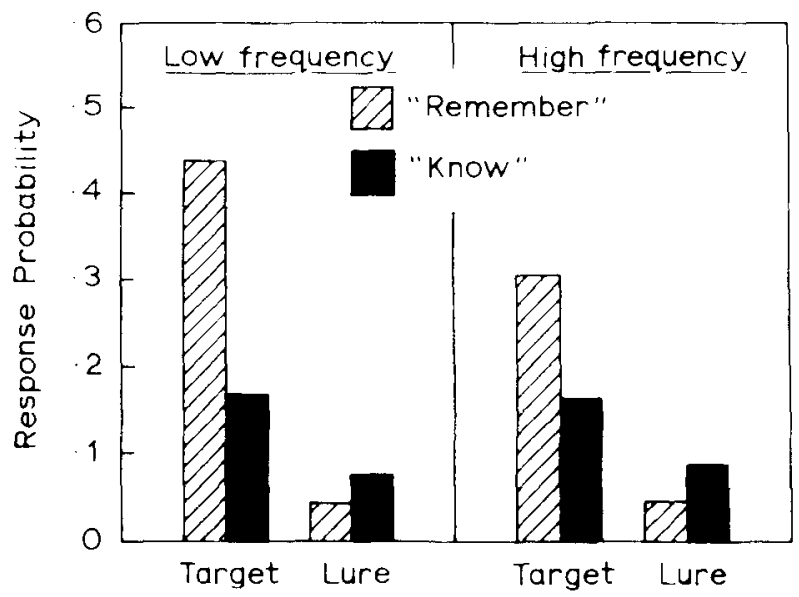

Figure 1. Response probability in the recognition of low-frequency versus high-frequency words.

\section{Results and Discussion}

Figure 1 summarizes the principal results, which are the mean probabilities of $R$ and $K$ responses for recognition targets and lures. Overall hit rates and false positive rates are given by the sum of these two types of response. The figure shows that in target recognition, word frequency influenced $\mathbf{R}$ responses but had no discernible effect upon $K$ responses. The figure also shows little effect of word frequency on false positive rates, but there is some indication that false positive rates were higher for $K$ than for $\mathbf{R}$ responses.

A separate analysis of variance (ANOVA) was carried out on individual subject responses to recognition targets and to lures. Following a precedent set by Gardiner (1988a), in these analyses, response type $-R$ versus $K-$ was treated as an independent variable, on the grounds that it may be regarded as an instructional manipulation. This assumption is, of course, questionable, but it does have the advantage that interactions involving response type can be directly evaluated. For target words, the results of the ANOVA showed that both the main effect of response type $\left[F(1,23)=41.76, M S_{\mathrm{e}}=14.37\right.$, $p<.001]$ and that of word frequency $[F(1,23)=19.68$, $\left.M S_{\mathrm{e}}=3.06, p<.001\right]$ were significant, and so too was the interaction between them $\left[F(1,23)=6.67, M S_{c}=\right.$ $7.23, p<.025$ ]. For lures, the results of the ANOVA showed that neither the main effect of word frequency nor the interaction between word frequency and response type were significant ( $F<1$ in each case); however, the main effect of response type was significant-but just barely $\left[F(1,23)=4.28, M S_{\mathrm{e}}=5.15, p=.05\right]$. A greater proportion of $K$ than $R$ responses to lure words was not found in Gardiner's (1988a) experiments, probably because false positive rates tended to be lower there than here.

Further analyses were undertaken to confirm that the proportion of $\mathrm{K}$ responses to target words reliably exceeded the proportion of $K$ responses to lures. It was indeed found to be so, both for low-frequency $[t(23)=3.36$, $S E=0.03, p<.001]$ and for high-frequency $[t(23)=$ 3.38, $S E=0.03, p<.001]$ words.

These findings therefore provide no evidence that the incidence of $\mathbf{K}$ responses was greater for low-frequency than for high-frequency words. Instead, the wordfrequency effect, like the levels-of-processing effect and the generation effect (Gardiner, 1988a), occurs only for recognition accompanied by recollective experience. This result is not consistent with the view that the wordfrequency effect is attributable to increased familiarity (Mandler, 1980) or perceptual fluency (Jacoby \& Dallas, 1981).

\section{EXPERIMENT 2}

The purpose of Experiment 2 was to compare "remember" and "know" measures of conscious awareness in recognition memory for nonwords and words. The point of this comparison was to see whether the recognition of nonwords might be associated with an increase in the in- 
cidence of "know" responses, a possibility suggested by evidence of enhanced perceptual fluency in nonword recognition (Johnston, Dark, \& Jacoby, 1985). The rationale was similar to that of Experiment 1. If perceptual fluency is enhanced for nonwords, relative to words, then there should be more "know" responses for nonwords than for words.

\section{Method}

Subjects. The subjects were a further 20 undergraduate students who were paid for their participation in the experiment and were tested individually.

Design and Materials. A set of 60 items -30 nonwords and 30 words-were chosen such that all items were of four-letter, onesyllable length. The nonwords were all readily pronounceable; items that obviously sounded like or looked like real words were avoided. The words were all chosen to be highly familiar. Examples of the nonwords are: JOSP, LORT, KLIB, ABST, and SOTE. Examples of the words are: WASH, GATE, SALT, YEAR, and MALE.

There were two alternate study lists, each consisting of 15 nonwords and 15 words. Half of the subjects received one study list; half received the other study list. The recognition tesi consisted of all 60 items from the complete set; hence, target items for half of the subjects were lure items for the other half. In this test, for each item the subjects recognized, they were asked to indicate whether they could or could not consciously recollect its prior occurrence in the study list.

Procedure. The procedure was similar to that of Experiment 1. Study lists were handprinted on a deck of cards and presented at the rate of $2 \mathrm{sec} /$ item in an order randomized separately for each subject. The subjects were told to memorize the items for a test to be given on the following day. The 24-h retention interval was again intended to reduce the risk of ceiling effects. For the test, all 60 items in the complete set appeared, in a single constant order, handprinted in 3 columns of 20 items each. The subjects were given test instructions similar to those given in Experiment 1.

\section{Results and Discussion}

Figure 2 summarizes the principal results, which are the mean probabilities of $\mathrm{R}$ and $\mathrm{K}$ responses for recognition targets and lures. The figure shows a quite different pattern of results for nonwords and words. Target recognition of nonwords, compared with words, was associated with a marked increase in the incidence of $K$ responses and a decrease in the incidence of $R$ responses. False positive rates did not differ much for nonwords and words, but false positive rates were higher for $K$ than for $R$ responses.

These findings were analyzed in a similar way to those of Experiment 1. For target items, the results of the ANOVA showed that neither the main effect of response type nor that of nonwords versus words were significant ( $F<1$ in each case), but the interaction between them was highly significant $\left[F(1,19)=18.66, M S_{\mathrm{e}}=4.08\right.$, $p<.001]$. For lures, the results of the ANOVA showed that neither the main effect of nonwords versus words nor the interaction with response type were significant $(F<1$ in each case); however, the main effect of response type was significant-this time, highly significant $[F(1,19)=$ $\left.16.99, M S_{c}=1.70, p<.001\right]$. The proportion of $\mathrm{K}$ responses to target items reliably exceeded the propor-

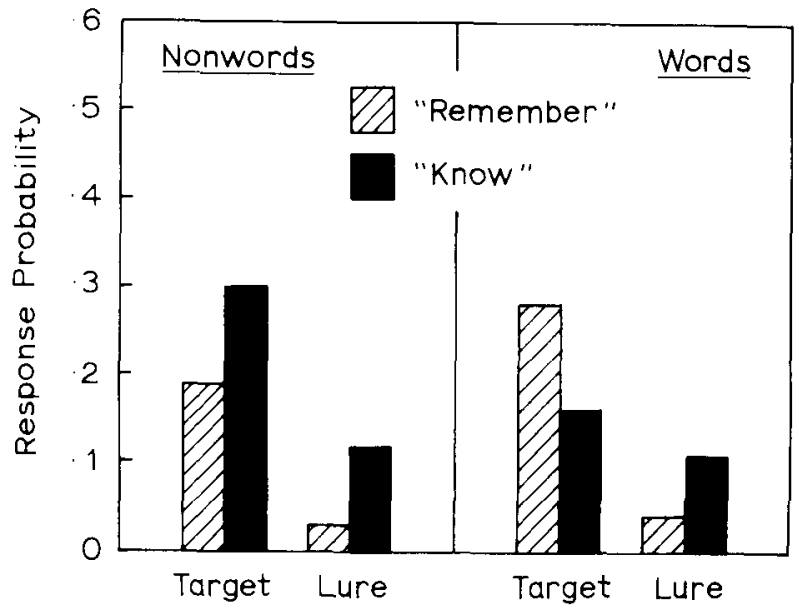

Figure 2. Response probability in the recognition of nonwords versus words.

tion of $\mathrm{K}$ responses to lures, both for nonwords [t(19) $=$ $3.66, S E=0.06, p<.001]$ and for words $[t(19)=2.48$, $S E=0.02, p<.025]$.

These findings demonstrate that the recognition of nonwords, compared with that of words, was reflected more in $\mathrm{K}$ responses than in $\mathrm{R}$ responses. Recollective experience was reduced in nonword recognition, and recognition was accomplished to a much greater extent in the absence of conscious recollection. This result is completely consistent with the view that perceptual fluency contributes more to nonword than to word recognition (Johnston et al., 1985). It therefore supports the hypothesis that "remember" and "know" measures reflect qualitatively distinct components of memory, rather than simple differences in trace strength.

The results of Experiment 2 also confirm the finding from Experiment 1 of higher false positive rates for recognition decisions made in the absence of recollective experience.

\section{EXPERIMENT 3}

A high level of recognition performance for "know" responses means that these responses cannot be equated with weak trace strength. But one might argue that if one were to take confidence, rather than performance, as an index of trace strength, then one might find that a high level of performance reflects an increase in the proportion of responses about which subjects are not very confident. For these reasons, Experiment 3 was designed to see whether the pattern of results obtained in Experiment 2 would also be obtained with confidence ratings. Specifically, the crucial question was whether nonword recognition, relative to word recognition, is associated with an increase in the proportion of decisions about which subjects are unsure.

Tulving (1985b) described a study in which subjects gave both "remember" versus "know" responses and 
confidence ratings in their recognition performance, and he found the two measures to be correlated quite highly. One would, of course, expect that recollective experience normally provides one basis for confidence in performance. But Tulving's procedure of having subjects give both confidence ratings and "remember" versus "know" responses at the same time might inflate the correlation between the two measures by encouraging subjects to base their confidence ratings on their recollective experience. For this reason, we decided to replicate Experiment 2 in all respects except that we had subjects give confidence ratings instead of "remember" versus "know" responses.

\section{Method}

Subjects. The subjects were a further 22 undergraduate students who were paid for their participation in the experiment and were tested individually.

Design, Materials, and Procedure. The design, materials, and procedure were identical to those of Experiment 2 except with respect to the recognition-test instructions. These instructions directed the subjects to give confidence ratings instead of measures of conscious awareness. To match the two measures as closely as possible, the subjects rated their confidence in each recognition decision using only a 2-point rating scale labeled "sure" and "unsure."

\section{Results and Discussion}

Figure 3 summarizes the principal results of this experiment. It is obvious from this figure that nonword target recognition was not associated with any increase in the proportion of decisions about which subjects were unsure, and that confidence ratings in target-item recognition do not show a similar interaction to that observed previously with measures of conscious awareness. The implication is that measures of conscious awareness are not simply equivalent to confidence ratings, even though, in general, it is probably true that subjects' confidence is correlated with their recollective experience. In this connection, it is worth noting that the confidence ratings of false positive responses did correspond with measures of conscious awareness, in that, for both words and nonwords, a greater proportion of false positive responses was associated with the "unsure" confidence rating.

For comparison purposes, we shall report analyses of these data similar to those reported for Experiments 1 and 2 , treating positive "sure" and "unsure" judgments in the same way as "remember" and "know" responses. For target items, the results of the ANOVA showed that there was a main effect of response type $[F(1,21)=5.03$, $\left.M S_{\mathrm{e}}=9.26, p<.05\right]$, but neither the main effect of nonwords versus words $\left[F(1,21)=1.34, M S_{c}=3.40\right]$ nor the interaction between them $\left[F(1,21)=1.42, M S_{\mathrm{e}}=\right.$ 2.59] was significant. For lures, the results of the ANOVA showed that the main effect of response type was highly significant $\left[F(1,21)=26.22, M S_{\mathrm{e}}=2.64, p<.0001\right]$, but neither the main effect of nonwords versus words $\left[F(1,22)=2.10, M S_{e}=2.62\right]$ nor the interaction between them $(F<1)$ was significant. The proportion of "unsure" responses to target items reliably exceeded the

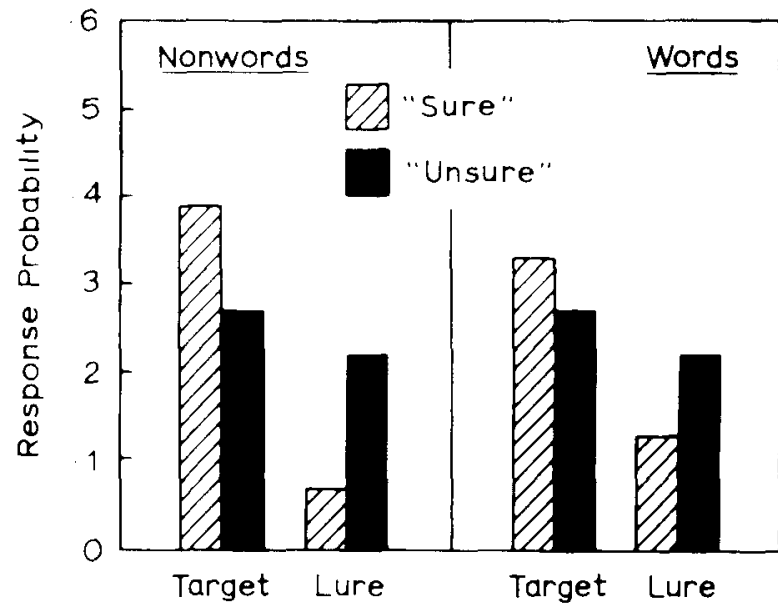

Figure 3. Confidence judgments in the recognition of nonwords versus words.

proportion of "unsure" responses to lures for nonwords $[t(21)=2.07, S E=0.01, p<.05]$, but not for words $[r(21)=1.48, S E=0.01, p<.10]$

\section{GENERAL DISCUSSION}

Recognition memory involves two measurable states of conscious awareness, one characterized by some specific recollective experience, one characterized by the absence of any such experience (Gardiner, 1988a; Tulving, 1985b). The goal of the present research was to provide further evidence about whether these two states of conscious awareness reflect qualitatively distinct components of recognition performance, rather than some unitary dimension such as trace strength. This dual-component hypothesis was suggested by the clear-cut dissociations previously observed with levels-of-processing and generation effects; neither of these effects occurred for words recognized in the absence of any recollective experience (Gardiner, 1988a). However, in those previous studies, recognition in the absence of recollective experience was not only uninfluenced by the independent variables, it was also associated with low levels of performance. This low level of performance makes it hard to completely discount the possibility that this state of conscious awareness simply reflects weak trace strength.

Three findings from the present experiments provide good support for the dual-component hypothesis: (1) recognition in the absence of recollective experience is not always associated with low levels of performance, (2) recognition in the absence of recollective experience responds systematically to some experimental manipulation, and (3) recognition in the absence of recollective experience is not merely equivalent to judgments about which subjects are relatively unsure.

The functional dissociations observed here and in previous, similar studies (Gardiner, 1988a) support the dualcomponent hypothesis, but we concede that they do not 
compel it. In particular, they do not provide evidence of reversed association, a form of dissociation that Dunn and Kirsner (1988) have argued is a sounder basis for making such claims than other, more common dissociations, including double dissociations. In addition, the acceptability of our conclusion depends on accepting the validity of the measures used. But the validity of these measures is attested by the patterns of results they produce: the data are highly principled. Also important in this connection is the finding that irrespective of differences in responses to recognition targets, false positives in both Experiments 1 and 2 included far more "know" than "remember" responses.

The argument that these two measures reflect something other than trace strength is not to deny that, as a general rule, stronger memories will be positively correlated with sharper recollective experiences and higher levels of confidence (Tulving, 1985b). The point is that strong memories are not invariably those that invoke some recollective experience, as, for example, when recognizing a very familiar person out of his or her normal context, and being quite unable to place the context or bring anything else to mind. In such circumstances, feelings of embarrassment are directly proportional to feelings of confidence about knowing who the person is. In a similar way, one might be confident about recognizing a nonword from a previous study list, and yet quite unable to bring back to mind anything about the occurrence of that nonword. With words, rather than nonwords, it is presumably much easier to encode specific aspects of the original context, and so to bring these back to mind in the recognition test. Thus, there is no real inconsistency between the relationships observed here among performance, confidence, and recollective experience and the relationships observed in Tulving's (1985b) study.

The present findings and conclusions are theoretically important for Tulving's (1983, 1985a, 1985b) distinction between episodic memory and other memory systems, and for dual-component theories of recognition memory, particularly those that assume that one of these components corresponds with familiarity (Mandler, 1980) or perceptual fluency (Jacoby \& Dallas, 1981) and gives rise also to priming effects in implicit memory.

In Tulving's (1983, 1985a, 1985b) scheme, recollective experience is a defining property of the episodic system, so "remember" responses may be thought to provide a relatively "pure" measure of output from this system. This position is strengthened by evidence that the word-freouency effect, like the levels-of-processing effect and the generation effect (Gardiner, 1988a), occurs only for recognition accompanied by recollective experience. The state of conscious awareness characterized by "know" responses is a defining property of the semantic memory system. Semantic knowledge is typically retrieved in the absence of any specific recollective experience. However, because nonwords have no semantic representation, the present findings indicate that this state of conscious awareness may also reflect some other form of memory. A plausible conjecture is that this other form of memory may be the quasimemory (QM) system that Hayman and Tulving (1989, in press) have proposed to account for priming effects in implicit memory. This is a "traceless" memory system that may be more closely related to procedural than to semantic memory. Its functional properties are assumed to include the major characteristics of implicit memory performance as summarized in Roediger et al.'s (1989) account of the transferappropriate processing approach (see also RichardsonKlavehn \& Bjork, 1988). Among these characteristics are a lack of sensitivity to conceptual factors and a greater dependence on data-driven factors. Moreover, information in the QM system is known to be highly resistant to forgetting (e.g., Sloman, Hayman, Ohta, Law, \& Tulving, 1988). In line with this conjecture, recognition memory in the absence of recollective experience has also been found to be quite resistant to forgetting. Over retention intervals ranging from 10 min to 1 week, "know" responses have been found to remain essentially unchanged, and virtually all the forgetting occurred only in "remember" responses (Gardiner, 1988a; Gardiner \& Java, 1989). Perhaps "know" responses in recognition memory provide a relatively "pure" measure of output from the QM system.

This conjecture is not problem-free, particularly because of the confused situation with respect to nonword priming effects (see Richardson-Klavehn \& Bjork, 1988, for a review; see also Duchek \& Neely, 1989). Especially problematic is evidence that amnesic patients do not show nonword priming either in perceptual identification (Cermak, Talbot, Chandler, \& Wolbarst, 1985) or in a nonword stem-completion task (Diamond \& Rozin, 1984). These results suggest that nonword priming effects in memory-unimpaired adults must be episodic in origin. On the other hand, there is more recent evidence that amnesic patients may show priming effects for nonwords, and that whether or not they do so depends on the etiology of the amnesia, not its severity (Cermak, Blackford, O'Connor, \& Bleich, 1988; Gordon, 1988). This evidence is important because it directly implicates some system other than episodic or semantic memory.

From the standpoint of two-component theories of recognition memory, "know" responses presumably correspond with familiarity (Mandler, 1980) or perceptual fluency (Jacoby \& Dallas, 1981), and "remember" responses reflect more elaborative, conceptually driven processing. These theories, too, are generally well supported by the present results and those of Gardiner (1988a). However, the finding that the word-frequency effect depends on conscious recollection, like levels-ofprocessing and generation effects, is not consistent with the view that increased familiarity or perceptual fluency accounts both for this word-frequency effect and for the enhanced priming of low-frequency words in perceptual identification. No comparable problem exists with respect to our comparison of nonword with word recognition, which directly supports the view that perceptual fluency 
is enhanced in nonword recognition (Johnston et al., 1985). We do not know how this apparent discrepancy in the perceptual fluency interpretation is to be resolved. But we suspect that its resolution may turn out to be connected with the finding that there is greater dependence between nonword recognition and perceptual identification than between word recognition and perceptual identification (Jacoby \& Witherspoon, 1982; Johnston et al., 1985).

Finally, it should be borne in mind that the distinction between the two states of conscious awareness measured by "remember" and "know" responses applies to individual items, not to the general experimental context. When giving a "know" response, it is only at the level of the individual item that subjects have no recollective experience; they can perfectly well recollect the presentation of the study list as a whole. This point is significant because it means that this kind of recognition memory may not be equivalent to source amnesia-that is, the finding that people may know some newly learned facts but not remember that these facts were acquired earlier in the experiment (e.g., McIntyre \& Craik, 1987; Schacter, Harbluk, \& McLachlan, 1984)-and because amnesics lack recollective experience at this global level, not just at the level of individual items.

Nevertheless, as Richardson-Klavehn and Bjork (1988) pointed out, memory-unimpaired adults may quite commonly have recollective experiences in implicit memory tests. Indeed, this was a major reason for RichardsonKlavehn and Bjork's preference for using the terms explicit and implicit memory to define states of conscious awareness rather than types of memory test. Furthermore, independence between explicit and implicit measures of retention does not seem to depend on subjects al ways being unaware, or uninformed, that the implicit test relates to a previously presented study list. For example, levelsof-processing effects occur in recognition memory but not in primed fragment completion, and recognition memory and primed fragment completion are stochastically independent, even though subjects are told that some fragments in the completion test are fragments of study-list words (see Gardiner, 1988b; Gardiner, Dawson, \& Sutton, 1989, for more discussion of this point). The independence arises simply from directing subjects to complete the fragments irrespective of what they remember from the study list. At least for memory-unimpaired subjects, the crucial difference between explicit and implicit memory performance seems to stem mainly from the set provided by the retrieval instructions. An explicit set directly engages conscious recollection. An implicit set attempts to disengage conscious recollection; it does not necessarily prevent it from occurring. And both sets can operate at the level of the individual list items with subjects being fully informed about the relationship between study and test lists.

One can define events at microlevel, as individual list items, or at macrolevel, as the entire experimental episode. This difference in the environmental nature of events may or may not correspond with some fundamental difference in the nature of mental experience and the relationship between mental experience and memory performance.

\section{REFERENCES}

Cermak, L. S., Blackford, S. P., O'Connor, M., Bleich, R. P. (1988). The implicit memory ability of a patient with amnesia due to encephalitis. Brain \& Cognition, 7, 312-323

Cermak, L. S., Talbot, N., Chandler, K., Wolbarst, L. R. (1985). The perceptual priming phenomenon in amnesia. Neuropsychologia, 23, 615-622

COltheArt, M. (1981). The MRC psycholinguistic database. Quarterly Journal of Experimental Psychology, 33A, 497-508.

DiAmond, R., Rozin, P. (1984). Activation of existing memories in anterograde amnesia. Joumal of Abnomal Psychology, 93, 98-105.

DUCHEK, J. M., NeELY, J. H. (1989). A dissociative word-frequency $\times$ levels-of-processing interaction in episodic recognition and lexical decision tasks. Memory \& Cognition, 17, 148-162

DUNN, J. C.. KIRSNER, K. (1988). Discovering functionally independent mental processes: The principle of reversed association. Psychological Review, 95, 91-101.

GArdiner, J. M. (1988a). Functional aspects of recollective experience. Memory \& Cognition, 16, 309-313

Gardiner, J. M. (1988b). Generation and priming effects in wordfragment completion. Joumal of Experimental Psychology: Learning. Memory, \& Cognition, 14, 495-501

Gardiner, J. M., Dawson, A. J., a Sutton, E. A. (1989). Specificity and generality of enhanced priming effects for self-generated study items. American Journal of Psychology, 102, 295-305.

GARdiner, J. M , \&AvA, R. I (1989). [Temporal aspects of conscious awareness in recognition memory]. Unpublished raw data.

Glanzer, M., ADAMS, J. K. (1985). The mirror effect in recognition memory. Memory \& Cognition, 13, 8-20.

GoRdon, B. (1988). Preserved learning of novel information in amnesia: Evidence for multiple memory systems. Brain \& Cognition, 7 , 257.282

GREGG, V. H. (1976). Word frequency, recognition, and recall. In J. Brown (Ed.), Recall and recognition (pp. 183-216). London: Wiley.

Hayman, C. A. G.. \& Tulving, E. (1989). Contingent dissociation between recognition and fragment completion: The method of triangulation. Joumal of Experimental Psychology: Learning, Memory, \& Cognition, 15, 228-240

Hayman, C. A. G.. \&ulving, E. (in press). Is priming in fragment completion based on a "traceless" memory system? Journal of Experimental Psychology: Learning, Memory, \& Cognition.

JACOBY, L. L. (1983). Remembering the data: Analyzing interactive processes in reading. Journal of Verbal Learning \& Verbal Behavior, 22, 485-508

JACOBY, L. L. (1988). Memory observed and memory unobserved. In U. Neisser \& E. Winograd (Eds.), Remembering reconsidered: Ecological and traditional approaches to the study of memory (pp. 145 177). New York: Cambridge University Press.

JACOBY, L. L., , DAllas, M. (1981). On the relationship between autobiographical memory and perceptual learning. Joumal of Experimental Psychology: General, 3, 306-340.

Jacoby, L. L., Kelley, C. M. \& Dywan, J. (1989). Memory attributions. In H. L. Roediger III \& F. I. M. Craik (Eds.), Varieties of memory and consciousness: Essays in honor of Endel Tulving (pp. 391422). Hillsdale, NJ: Erlbaum.

JACOBY, L. L.. WITHERspoon, D. (1982). Remembering without awareness. Canadian Journal of Psychology, 36, 300-324.

Johnston, W. A., DARK, V. J.. JaCoBy, L. L. (1985). Perceptual fluency and recognition judgments. Joumal of Experimental Psychology: Learning. Memory, \& Cognition, 11, 3-11.

KuCERA, H., Francis, W. N. (1967). Computational analysis of present-day American English. Providence, RI: Brown University Press. 
Mandler, G. (1980). Recognizing: The judgment of previous occurrence. Psychological Review, 87, 252-271.

MandleR, G. (1988). Memory: Conscious and unconscious. In P. R. Solomon, G. R. Goethals, C. M. Kelley, \& B. R. Stephens (Eds.), Memory: Interdisciplinary approaches (pp. 84-106). New York: Springer-Verlag.

MCINTYRE, J. A., \& Craik, F. I. M. (1987). Age differences in memory for item and source information. Canadian Journal of Psychology, 41, 175-192.

Richardson-Klavehn, A., \& Bjork, R. A. (1988). Measures of memory. Annual Review of Psychology, 39, 475-543.

Roediger, H. L., III, Weldon, M. S., \& Challis, B. H. (1989). Explaining dissociations between implicit and explicit measures of retention: A processing account. In H. L. Roediger III \& F. I. M. Craik (Eds.), Varieties of memory and consciousness: Essays in honor of Endel Tulving (pp. 3-41). Hillsdale, NJ: Erlbaum.

SCHACTER, D. L. (1987). Implicit memory: History and current status. Journal of Experimental Psychology: Learning, Memory, \& Cognition, 13, 501-518.

Schacter, D. L., Harbluck, J. L., \& Mclachlan, D. R. (1984). Retrieval without recollection: An experimental analysis of source amnesia. Journal of Verbal Learning \& Verbal Behavior, 23, 593-611.

Shimamura, A. P. (1986). Priming effects in amnesia: Evidence for a dissociable memory function. Quarterly Journal of Experimental Psychology, 38A, 619-644.

Sloman, S. A., Hayman, C. A. G., Ohta, N., Law, J., \& TulvING, E. (1988). Forgetting in primed fragment completion. Journal of Experimental Psychology: Learning, Memory, \& Cognition, 14, 223-239.

Tulving, E. (1983). Elements of episodic memory. New York: Oxford University Press.
Tulving, E. (1985a). How many memory systems are there? American Psychologist, 40, 385-398.

Tulving, E. (1985b). Memory and consciousness. Canadian Psychologist, 26, 1-12.

Tulving, E. (1989). Memory: Performance, knowledge, and experience. European Journal of Cognitive Psychology, 1, 3-26.

Tulving, E., Schacter, D. L., \& Stark, H. A. (1982). Priming effects in word-fragment completion are independent of recognition memory. Journal of Experimental Psychology: Learning, Memory, \& Cognition, 8, 336-342.

WatKINS, M. J. (in press). Mediationism and the obfuscation of memory. American Psychologist.

\section{NOTE}

1. In some studies in which we have measured "remember" and " "know" responses, though not those reported here, a few subjects have clearly failed to understand or act upon this distinction. In nearly every case, these subjects responded as if "know" meant "certain." Such cases are indicated by an exceptionally high preponderance of "know" responses, and they can be confirmed by going through a subject's responses with that subject after the testing session. The present instructions were designed to ensure that the subjects did not interpret a "know" response to mean the same thing as poor memory, by giving the example of knowing one's own name. The general aim of the instructions was to prevent "remember" and "know" responses from being interpreted in terms of "goodness of memory," and to pin the distinction entirely to the mental experience that accompanies the memory.

(Manuscript received December 14, 1988; revision accepted for publication June $5,1989$. ) 